\title{
SINGUIJAR CASE OF MONS'TROSITY.
}

[Communfeated for the Boston Medical and Surgicul Journal.]

$\mathrm{O}_{\mathrm{N}}$ the 13th of July I was requested to visit Mrs. —, ship-carpenter's wife, in labor with her first child. I found the vertex presenting, and at first considered I had only a natural case to manage. After nine hours' labor, she was given an infusion of half a drachm of secale cornutum, which was repeated in an hour, and in two hours after the last dose the head was born without manual assistance. After the delivery of the head, I anticipated difficulty, and called my friend Dr. John Polhemus in consultation. A donble foot and one arm presented. The hand we returned, but we made no attempt to return the foot. As, notwithstanding severe pains, the labor made no further progress, and as we had every reason to believe the child was dead, we drew the head with very considerable force, actingr with it as a lever simultaneously with the contractions of the uterus, and by gradual management and perseverance we delivered the foetus. In fifteen minutes the placenta came away, and the patient, though much exhausted, soon recovered, and is now able to attend to the domestic concerns of her family.

The peculiarities of the foetus are the object of this communication. It had two perfect heads and other parts of the upper half of the body, united, base to base, at the umbilicus. From one side of the bodies thus joined, one thigh and leg, with a double foot, projected; and from the other, two thighs, legs and feet. There was an anus at the posterior portion of the junction of the bodies, but there were no appearances of urethra or organs of generation. Its weight was eleven pounds; and its length, from one vertex to the other, was twenty-two inches.

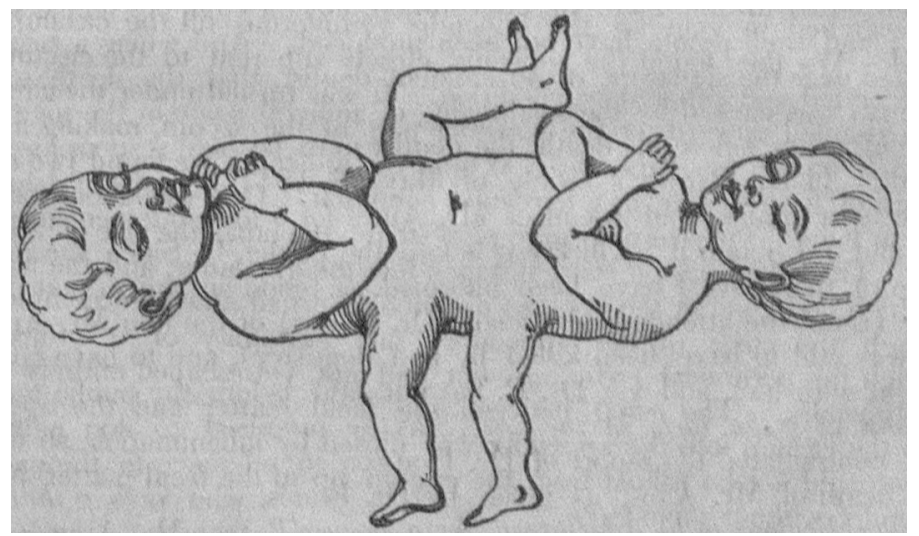

The accompanying figure will convey a better idea of the form of the monstrosity, than words. As I have not heard of a similar case, I forward this communication for insertion, if you think proper, in your valuable Journal.

Nyack, N. Y., August 15, 1847.

W. J. Johnston, M.D. 